January 2017

\title{
mHealth in palliative care for cancer patients \& care givers
}

Newton Andebe

University of Nairobi

Peter Waiganjo

University of Nairobi

John Weru

Aga Khan University, john.weru@aku.edu

Follow this and additional works at: https://ecommons.aku.edu/eastafrica_fhs_mc_intern_med Part of the Internal Medicine Commons, and the Oncology Commons

\section{Recommended Citation}

Andebe, N., Waiganjo, P., Weru, J. (2017). mHealth in palliative care for cancer patients \& care givers. 2017 IST-Africa Week Conference (IST-Africa), 1-10.

Available at: https://ecommons.aku.edu/eastafrica_fhs_mc_intern_med/91 


\title{
mHealth in Palliative Care for Cancer Patients \& Care givers
}

\author{
Newton ANDEBE ${ }^{1}$, Peter WAIGANJO ${ }^{1}$, John WERU ${ }^{2}$ \\ ${ }^{1}$ University of Nairobi, P.O. Box 30197 - 00100, Nairobi, Kenya, \\ +254 728324574, Email:newtonandebe@gmail.com \\ Tel: +254 723 488114, Email: waiganjo@uonbi.ac.ke \\ ${ }^{2}$ Aga Khan University Hospital, P.O. Box 30270-00100. Nairobi, Kenya. \\ Tel: +254 722676 711, Email: john.weru@aku.edu
}

\begin{abstract}
Patients and caregivers in palliative care experience multidimensional pain. In current practice, information about a cancer patient progress is known when they visit a clinic or make a distress call when their conditions worsen. This strategy is not efficient for systematic monitoring of symptoms, which is key in improving palliative care. Mobile phones have helped to transform healthcare through diagnosis, health education and symptoms management of chronic illnesses. In this study, a mobile phone assessment tool was implemented at an outpatient palliative care clinic for cancer patients in Aga Khan University Hospital, Nairobi. The usefulness of the mobile phone application was examined. In the initial interview with a cohort of 19 patients and caregivers, 15 were eligible for the study. Patients and caregivers used the application to report their symptoms and needs at an interval of one week. Participatory action design was used whereas data collection was achieved through non-structured interviews. Findings from the study were organized into three themes: enhanced communication, improved assessment of total cancer pain and advocacy tool. This study illustrates that utilization of mobile phone applications can enhance palliative care by improving monitoring of symptoms and strengthening patient-provider communication.
\end{abstract}

Keywords: Palliative Care, Symptoms Assessment, Cancer Pain, mHealth

\section{Introduction}

The main goal in palliative care is to improve quality of life of patients and their families facing problems of life threatening diseases [1]. Numerous symptoms affect patients undergoing palliative care, which has an impact on their psychological well-being and quality of life [2-4]. Lack of sufficient communication leads to increase in stress, insufficient patient satisfaction and decrease in strictly following medical recommendations [5]. In order to attain high quality of care in palliation, consistent and systematic reporting of symptoms is essential [6-7]. Efficient collection of data at a palliative care setting assists to inform better quality of patient care [8].

Despite growth in Information Technologies, few studies exist to link Information and Communication Technology (ICT) to long term diseases and palliative care [9]. A study on use of mobile phone applications in long-term diseases indicated that $63 \%$ of applications developed concerned diabetes with only 5\% covering Cancer [10]. There is need for units dealing with palliative care to engage on research on quality of data that can be used to inform best practice. Quite often paper based questionnaires are used in clinical practice, changing them into data that can be accessed instantly for clinical purposes pose a great challenge [11].

An example of previous usage of technology in palliative care involved usage of a pager for symptoms assessment at a Scottish oncology centre [12]. Telemedicine usage among 
head and neck cancer patients in Erasmus MC, a tertiary university hospital in Netherlands revealed an improvement in quality of life among the intervention group that used a laptop for symptom management [13]. Web based systems have also been used to monitor cancer patients status [14]. For instance, a clinical reporting tool was developed and was accessed using a desktop [15]. The drawback was the fact that advanced patients with cancer could not be able to utilize it thus care givers used it more than the patients. Handheld devices have also been used to collect patients' status as they made clinical visits [16]. A handheld tablet was used to collect patient outcome as they visited Duke Comprehensive Cancer centre [17]. The tool had 80 item questionnaire for men and 86 items for women in varying domains. The limitation of the tool was the large number of items; our study utilized 10 items, which is faster.

A clinician reporting tool was implemented for two types of advanced cancer namely breast and prostate in five major cancer centres in the North Eastern, Midwestern and South-western United States [18]. The Clinical reporting tool was based on a set of questions deemed important to indicate status of the cancer patient. Measurements utilized included Edmonton Symptom Assessment Scale and Karnofsky Performance Scale. It is worth noting that utilization of information technology tools helped to strengthen communication in cancer care [19].

Several studies exist where mobile phone applications have been used in cancer and palliative care $[20,23,24]$. The applications were found useful; however, none of the studies have been conducted within an African context. Findings from the state of palliative care in three countries, Kenya, Uganda and Malawi shows the caregivers or patients could flash the health workers who in turn called up to follow the patients status [22].

Other tools developed for pain assessment in cancer patients include usage of a digital pen and mobile technology platform [22]. One of the challenges in the study was how to use a visual analog scale. Limited evidence exists on how effective e-health intervention has had on palliative care patients [25]. Outcomes from a study carried in rural Bangladesh on managing symptoms in 10 breast cancer patients using a mobile phone indicated there was improvement on familiarity of breast cancer, improved assessments and real time pain management [26]. Presently, there is limited knowledge on how mobile phone applications can be used in managing total cancer pain within an African context. It is with this background that this study seeks to address this gap.

\section{Objectives}

Our study aimed to assess change in quality of palliative care for cancer patients at Aga Khan University Hospital by use of mobile phone enabled assessment tools. Therefore, we developed a mobile phone tool for reporting symptoms of cancer patients and care giver needs. Finally, we examined usefulness of the tool.

\section{Methodology}

\subsection{Design}

Participatory action research (PAR) design was utilized in this study. PAR is a reflective process where researchers and participants undertake with a goal of understanding and improving the practices and situations they find themselves in [27]. The reflective process involves planning of a desired change, action and observation of the process and the outcomes of the change $[27,28]$.

In action research, a phenomena of interest is investigated with a provision of an intervention to solve a given problem [28]. PAR design is described to have five phases namely diagnosing, action planning, and action taking design intervention, impact evaluation, and learning and creation of actionable knowledge for the client. 


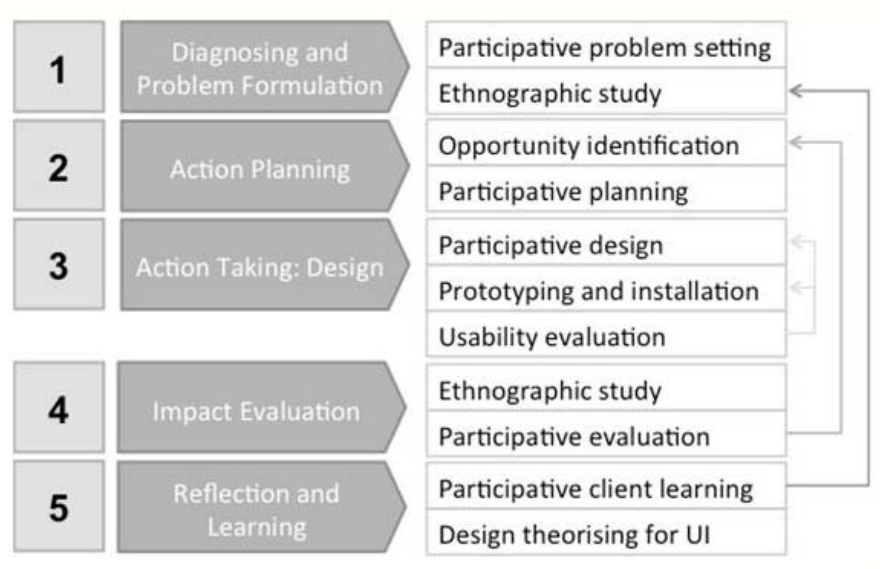

Figure 1: PAR Design Model (Adopted from [28]).

This is illustrated in the PAR design model presented in Figure 1.

a) Diagnosing a problem: Through interaction with stakeholders a problem is identified and an agreement on how to solve the problem is reached. In this study, needs assessment were made through interaction with cancer patients, oncology nurses and palliative care physicians.

b) Action Planning: This entails transformation of the findings from diagnostic stage to a collaborative work plan by the stakeholders on how to resolve the problem. This study involved the patients, doctors and nurses in working towards forming a feasible solution.

c) Action Taking: This refers to design and development of the artefact. It involves three steps namely: participative design, prototyping and installation, usability evaluation. A prototype was designed and installed on patient's mobile phone, doctors' computers and mobile phones.

d) Impact Evaluation: This is an assessment on whether the desired objectives of the project have been attained.

e) Reflection and Learning: At the end of the study, stakeholders took time to consider the lessons acquired in the study.

\subsection{Setting}

The location of the study was Aga Khan University Hospital in Nairobi, Kenya. The outpatient clinic dealing with palliative care in Cancer was used.

\subsection{Participants}

The population that was initially interviewed in the study involved one palliative care nurse, one palliative care physician , 9 cancer patients and 10 caregivers who attended the outpatient Palliative care clinic at Aga Khan University Hospital . 15 patients and caregivers were eligible. Table 1 shows a summary of patients and caregivers who participated in the study.

Table 1: Summary of data on patients and caregivers

\begin{tabular}{|l|l|l|l|}
\hline Characteristic & & Patients (n=8) & Caregivers(n=7) \\
\hline Mean age in Years (range) & & $53(19-77)$ & $41(28-59)$ \\
\hline Gender (No. \& Percentage) & Male & $2(25 \%)$ & $3(43)$ \\
\cline { 2 - 4 } & Female & $6(75 \%)$ & $4(57)$ \\
\hline $\begin{array}{l}\text { Previous Use of Applications } \\
\text { (No. \& Percentage) }\end{array}$ & None or little & $6(75 \%)$ & $1(14)$ \\
\hline & Quite a lot & $2(25 \%)$ & $6(86)$ \\
\hline
\end{tabular}




\begin{tabular}{|l|l|l|l|}
$\begin{array}{l}\text { Communication between Visit } \\
\text { (No. \& Percentage) }\end{array}$ & None or little & $8(100 \%)$ & $7(100 \%)$ \\
\hline & Quite a lot & $0(0 \%)$ & $0(0 \%)$ \\
\hline Location (No. \& Percentage) & Within Nairobi & $2(25 \%)$ & $2(29 \%)$ \\
\hline & Outside Nairobi & $6(75 \%)$ & $5(71 \%)$ \\
\hline
\end{tabular}

\subsection{Sample size estimation}

Purposive Sampling was utilized. In purposive sampling, participants are selected if they meet certain characteristics of a study [29]. A similar research on monitoring breast cancer symptoms using a mobile phone utilized 10 patients [30]. A study on a technical solution to improve palliative care at University of Texas Anderson utilized 18 patients and caregivers [28]. Another study that aimed to find out usability of a mobile phone application in cancer illness management utilized 7 cancer patients [31].

\subsection{Eligibility Criteria for Cancer patients}

It was necessary for participants to be 18 years of age and above. Secondly, the patient/caregiver needed to have a smart phone. Thirdly, a consent form was signed by the study participants (patient and caregiver). Finally the patient/caregiver was expected to be sufficiently cognitive.

Of the participants interviewed, fifteen patients and caregivers who were deemed eligible. The mobile application was installed on participants' smartphones. The study was undertaken over a six-week period of time from 25th January 2016 to 4th March 2016.

\subsection{Data Collection}

Data was collected using structured face-to-face interviews between the investigator, patients and their caregivers and palliative care physicians. The average time taken for the interview was 30 minutes in an enclosed room and a private enclosure.

\section{Technology Description}

Prototype development consisted of client and server side. Client side was implemented using Java-Android whereas PHP and MySQL was used for server side. MySQL database is a relational database system, which supports client/server architecture. We adopted MySQL since it is a free, powerful, open source database management system, which is also easy to use. In addition, it is fast and platform independent. Data collected by patients, caregivers and physicians was stored in this platform.

PHP was used to connect the android application with the MySQL database. PHP is a scripting language where its processing happens in the server by consuming server's resources and sends only the output to the client to interact with databases. A combination of PHP and MySQL database were utilized to develop an Application Programming Interface (API). The API accepted requests in POST/GET methods and interacted with MySQL database through fetching/inserting data.

Android studio provided an app development platform for Integrated Development Environment (IDE). Some key features of Android Studio include: live layout; androidspecific refactoring and quick fixes; lint tools to catch performance, usability, version compatibility and other problems; proguard and app-signing capabilities; template-based wizards to create common android designs and components; a rich layout editor that allows users to drag-and-drop UI components, option to preview layouts on multiple screen configurations.

The size of the developed application was $2.74 \mathrm{MB}$. Bluetooth technology was used to transfer the installation file (apk) from the investigators' phone to patient/caregiver phones. 
The pilot study took 6 weeks and two patients passed on during the period. 2 patients were extremely sick; therefore caregivers' phones were used to submit patients' progress.

The potential of the application is great considering the increasing rate of mobile phone penetration in Africa. Statistics show that in 2015, the mobile phone penetration in Africa was 47\% [35]; in Jan 2016, the mobile phone penetration in Kenya was $88 \%$ [36] whereas in Ghana the rate was $136.4 \%$ as at December 2016 [37]. With a rapid increase of cancer in cases [38], a wide population will find the mobile application useful.

\section{Developments}

The main functionalities of the system include collection of data, transmission of data, and visualization of data through a web interface, generation of alerts in form of Short Message Texts (SMSs). Data was collected using the mobile phone application. Patients and caregivers filled a questionnaire, which inquired on their different health status. The questionnaire was based on African Palliative Care Association African Palliative Care Outcome scale (APCA African POS), the only palliative outcome scale validated for use within an African context [34]. The questions in APCA African POS dealt with physical pain, symptoms, spiritual care, family and patient needs. For patients that were weak, care givers assisted in administration of the questions through the mobile application tool. The data was stored in MySQL database (assessment table). A threshold value of 3 out of 5 was set for each condition such that when it was exceeded, an SMS was generated to the physician's phone. The physician accessed the patients/caregiver data through a web interface in their computer. He was also able to log into the system through a mobile phone to view desired data. Graphs indicated the trend of the patient/caregiver in a particular parameter. Parameters of the study included pain, symptoms, worry, share, life worth, peace, help advice, family information, family confidence and family worry. Time of posting the data was also included.

The physician received an SMS alert in case a patient/caregiver reported a state that was above the threshold value. For instance in the parameter of pain, value 0 indicated low pain whereas value 5 indicated high level of pain. When a value greater than 3 was submitted, an alert was sent to the physician who thereafter advised the patient/caregiver appropriately on the course of action to undertake. Figure 1, Figure 2 and Figure 3 show screenshots of the application

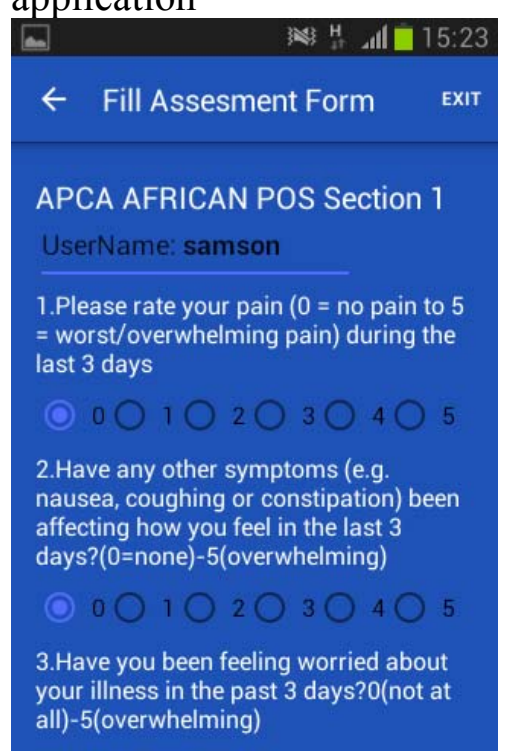

Figure 1: Assessment form on the Mobile App

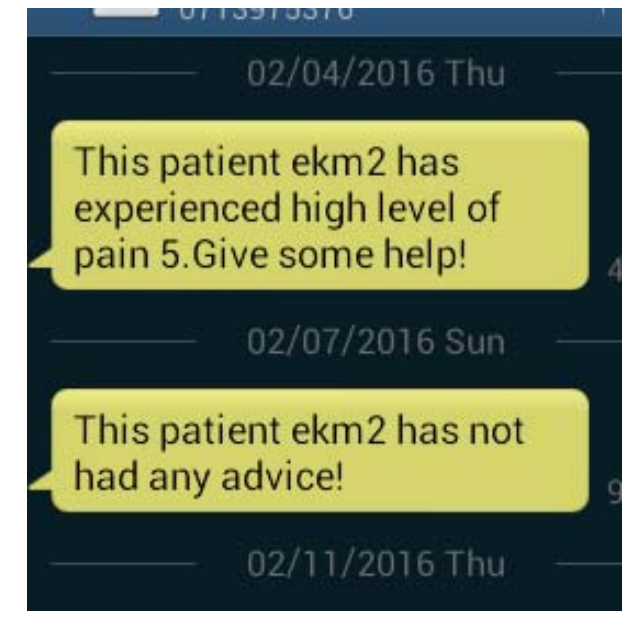
Figure2: SMS Alert as sent to the
physician

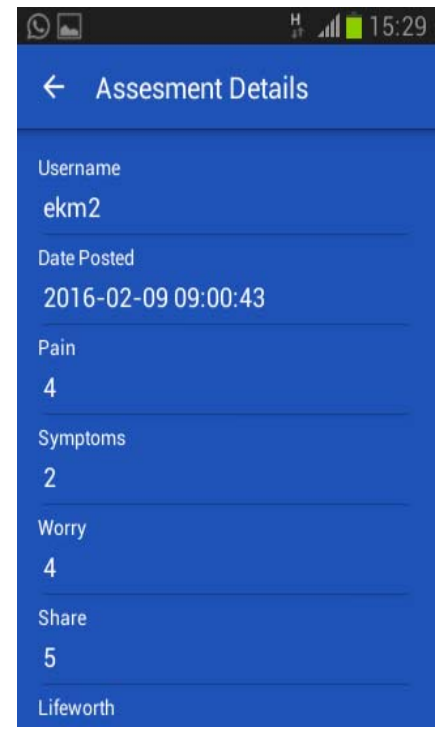

Figure 3:Assesment details of one patient 


\section{Results}

Themes emerging from closing interviews were communication, symptoms management and advocacy. 5 out of 7 groups of participants were interviewed through mobile phone during the closing interview. In 1 out of 7, there was a face-to-face interview. During the study, 2 patients passed on.

The following emerging themes and excerpts of conversation were highlighted:

\subsection{Enhanced communication}

Communication is the aspect of exchanging information, messages, and ideas between people thereby enabling better understanding of issues at hand. In our study, enhanced communication between palliative care physicians and patients/caregivers was evident from the following excerpts;

Caregiver C8 mentioned the application enabled him to communicate better "This one is much better than the SMS method which i just tell the doctor that the patient is doing well. At least the doctor is able to know how my niece is doing in a better way".

$\mathrm{C} 1$ highlighted the mobile application was a good approach but since the patient had been admitted, he had not been able to continue using the application. "The application in itself is good but my wife became very ill and has been admitted, at the moment, we don't know what is next (looking up), we pray all goes well".

Patient P7 highlighted the application was useful for communication and noted that with addition of a reminder on when to submit the data on a regular basis, the mobile application would be better. "I kept forgetting to send the update on time, i only wish there was a reminder even in form of a message. I know it is a good way to communicate"

Commenting on the message notifications alert, one physician noted that the feature was helpful in knowing which particular dimension of care needed attention. At the closing interviews, patients and caregivers agreed the application had helped to improve communication between them and the physicians.

\subsection{Advocacy tool}

Advocacy is the act of supporting or making recommendation for a particular cause. In our study, pain management in cancer is the centre of advocacy. The mobile phone application played an important role as a mechanism to disseminate knowledge on management of aspects of total cancer pain as well as platform for learning. In an instance of caregiver C2, a relative who stayed with caregiver was interested in learning about the mobile phone application and was able to make a submission. "My relative who also assists in taking care of grandma also wanted to learn how to send these symptoms, so i taught him". Therefore with more training on utilization of the mobile application for symptoms, more awareness on cancer in society can be achieved. Caregiver C4 noted she had been greatly informed on how to take care of the patient through information provided in the mobile application. "I have been going through the resources provided and I have learnt a lot on managing pain”

\subsection{Improved assessment of total cancer pain}

Pain in cancer does not only involve physical pain but is also caused by social, psychological and spiritual distress. The different pains have to be accurately identified so that the relevant appropriate action is taken to assist the patient. It was noted by the physician that assessment of patient/caregivers had improved. In our study, graphs that cover all dimensions of palliative care were generated. Through the graphs, it was possible to follow patients and caregivers trend in care. This was able to inform decision making in provision of palliative care. 
In addition, when a consistent high alert was generated on a parameter such as pain, the palliative care physician made adjustments on dosage of drugs that had been prescribed.

Commenting on $\mathrm{P} 2$ the palliative care physician noted "The patient was not able to access the recommended drugs in the new medical facility they went to, as a result, the health deteriorated".

It is worth noting for P8 that the worry levels had decreased. The palliative care physician commented "Initially P8 had a lot of worry, after discussions, i learnt it was as a result of finances. However, the hospital has been able to help her and more assistance has been given by the nephew". The psychological aspect of pain was therefore addressed in time.

\section{Business Benefits}

Our mobile phone application improves clinical care through early notification of key patient symptoms and caregiver needs. As a result better patient/caregiver satisfaction is achieved. In addition, patient provider communication is enhanced.

Using the application also helps in saving time during clinical visits since symptoms are reported in advance before an encounter with a clinician. The clinician will therefore spend more time in addressing the pertinent symptoms raised by the patient.

Improvement in accuracy of symptoms assessment and timely response to needs and symptoms will also be achieved. This would help in reduction of healthcare costs since a deteriorating health condition will be addressed before it worsens. Patients/caregivers who stay in locations with poor transport infrastructure and healthcare facilities can be monitored remotely, thus saving on transport costs.

Researchers and health professionals will also have more elaborate evidence on outcomes of palliative care hence develop effective strategies to improve service delivery.

\section{Conclusions}

This study presented the implementation of a mobile phone based assessment tool in palliative care. Our key findings include: improved patient-provider communication, improved symptoms management and provision of an advocacy platform for cancer. This is consistent with findings from other studies on using mobile technology in palliative care for cancer patients [26][30]. Aged patients expressed willingness to utilize the application despite limited interactions with technology. Feasibility results on usage of technology among elderly people indicate they were willing to use mobile phone applications to improve their health [32]. Caregivers and patients were trained on using the application and managed to work together with patients in submission of data. Our prototype presents a platform where both the caregivers' needs and the patients' needs are addressed.

There is a need to promote multidimensional and brief patient reported outcome measurements which comprise of physical and psychological domains [33]. Our study shows implementation of the mobile version of APCA African POS will add greatly to the benefits accrued in palliative care through use of patients outcome scale (POS). In addition, we suggest that the problem of marketing the POS will also be addressed [39].

Challenges included a high rate of attrition in cancer patients attending a palliative care section. Many patients sought palliative care services at an advanced stage of their illness. In a new study, life expectancy of a patient could be considered as eligibility criteria. Another challenge was the fact that the study was conducted in one centre, therefore, generalizability of the study is not possible; to overcome this, the study can be conducted in several palliative care centres. Lastly, only Android mobile phones were supported by our mobile phone application. Developers in healthcare applications could consider implementation of this prototype on a feature phone. 


\subsection{Recommendations/Future directions of the Research}

Our study was affected by time constraints; we recommend collection of data for three months followed by a clinical trial for a period of 6 months in a number of palliative care centres. The clinical trial can be done with two arms of study (control and intervention groups). We shall be able to realize how different parameters differ quantitatively after being subjected to the intervention tool. Having this in place, the application can be available in one year's time. We also recommend incorporation of an automatic feedback response, which could be tailored to a patient/caregiver's needs using an algorithm.

\subsection{Bringing Technology to the African Market}

We intend to achieve this by collaborating with Africa Palliative Care Association to assist in advocacy and deployment of the application within Africa. In, addition, we shall work with hospices, organisations public and private hospitals that deal with palliative care.

\section{References}

[1] World Health Organization. Definition of palliative care. 2008;

http://www.who.int/cancer/palliative/definition/en/ Accessed (July) 27, 2015.

[2] Cleeland, C.S. 2007. Symptom burden: multiple symptoms and their impact as patient reported outcomes, J Natl Cancer Inst Monogr, 37:16-21

[3] Barbera, L., Seow, H., Howell, D., Sutradhar, R., Earle, C.,Liu, Y., Stitt, A., Husain, A., Sussman, J. and Dudgeon, D. 2010 Symptom burden and performance status in a population-based cohort of ambulatory cancer patients. Cancer. 116:5767-5776.

[4] Kirkova, J.W.D and Aktas, A. 2012 Symptom Prevalence in Advanced Cancer: Age, Gender, and Performance Status Interactions. Am J Hosp Palliat Care. 29:139.

[5] Reisa, A., Pedrosab, A., Douradoc, M. and Reisd, C. 2013 Information and Communication Technologies in Long-term and Palliative Care.2013; Procedia Technology. 9:1303 - 1312

[6] Homsi, J., Walsh, D., Rivera, N., Rybicki, L.A., Nelson, K.A., Legrand, S.B., Davis, M., Naughton, M., Gvozdjan, D., Pham, H. 2006, Support Care Cancer ;14: 444-453

[7] Currow, D.C., Allingham, S.,Yates, P., Johnson, C., Clark, K. and Eagar, K. 2015. Improving national hospice/palliative care service symptom outcomes systematically through point-of-care data collection, structured feedback and benchmarking, Support Care Cancer., 23(2):307-15.

[8] Kama,1 A. H., Currow, C.D., Ritchie, C., Bull, J., Wheeler, J.L. and Abernethy, A.2011. The Value of Data Collection within a Palliative Care Program, Curr Oncol Rep., 13:308-315.

[9] Reisa, A., Pedrosab, A., Douradoc, M. and Reisd, C. 2013. Information and Communication Technologies in Long-term and Palliative Care. Procedia Technology, 9:1303 - 1312

[10] Fiordelli, M., Diviani, N., Schulz, P.J. 2013 Mapping mHealth research: a decade of evolution. J Med Internet Res., doi: 10.2196/jmir.2430

[11] Bennett, V.A., Jensen, R.E. and Basch, E. 2012. Electronic Patient-Reported Outcome Systems in Oncology Clinical Practice, CA Cancer J Clin. , 62:336-347

[12] Van den Brink J.L., Moorman, P.W., De Boer, M.F., Wim, C.J., Jean, F.A.P., Carel, D.A.V. and Jan, H.V. 2007, Impact on Quality of Life of a Telemedicine System Supporting Head and Neck Cancer Patients: A Controlled Trial during the Postoperative Period at Home. J Am Med Inform Assoc., 14:198-205. doi:10.1197/jamia.M2199

[13] Dubenske, L.M., Dinauer, S., Gustafson, D., Cleary, J.F.2008, Development and Implementation of a Clinician Reporting System for Advanced Stage Cancer: Initial Lessons Learned ,J Am Med Inform Assoc., 15:679-686

[14] Snyder, C,F., Jensen, R., Courtin, S.O., Wu, A.W. 2009. Website for outpatient QOL assessment research network. patient viewpoint: a website for patient-reported outcomes assessment, Quality of Life Research: An International Journal of Quality of Life Aspects of Treatment, Care and Rehabilitation. 18(7),793-800.

[15] Snyder, C.F., Jensen, R., Courtin, S.O., Wu, A.W. 2009. Website for Outpatient QOL Assessment Research Network. Patient Viewpoint: a website for patient-reported outcomes assessment, Qual Life Res 18:793-800.

[16] Abernethy, A.P., Herndon, J. E., Jane, L., Wheeler, J. L., Patwardhan, M., Shaw, H.H., Kim Lyerly, K. and Weinfurt, K. 2009 Improving Health Care Efficiency and Quality Using Tablet Personal Computers to Collect Research-Quality, Patient-Reported Data, J. Pain Symptom Manage. Vol;37 pp 1027-1038 
[17] Abernethy, A. P.,Herndon, J. E., Jane L. Wheeler, J. L., Patwardhan, M., Shaw, H.H., Kim Lyerly, K. and Weinfurt, K. (2009) Improving Health Care Efficiency and Quality Using Tablet Personal Computers to Collect Research-Quality, Patient-Reported Data, J. Pain Symptom Manage. Vol;37 pp 1027-1038

[18] Dubenske, L.M. Dinauer, S., Gustafson, D. and Cleary J. F. 2008. Development and Implementation of a Clinician Reporting System for Advanced Stage Cancer: Initial Lessons Learned, J Am Med Inform Assoc., 15, 5,679-686

[19]Quillin, J.M., Tracy, K., Ancker, J.S., Mustian, K.M., Ellington, L., Viswanath, V., Miller and M.S. 2009. Health Care System Approaches for Cancer Patient Communication, Journal of Health Communication: International Perspectives, 14: 85-94.

[20] McCann, L., Maguire, R., Miller, M. and Kearney N. 2009, Patients' perceptions and experiences of using a mobile phone-based advanced symptom management system (ASyMS) to monitor and manage chemotherapy related toxicity. Eur J Cancer Care , 18:156-164.

[21] Lind, L. and Karlsson D. 2004 A system for symptom assessment in advanced palliative home healthcare using digital pens. Med Inform Internet, 29(3-4), 199-210.

[22] Grant, L., Brown, J., Leng, M., Bettega, N. and Murray, A.S. 2011. Palliative care making a difference in rural Uganda, Kenya and Malawi, three rapid evaluation field studies, BMC Palliative Care , 10,8 doi: 10.1186/1472-684X-10-8.

[23] Jibb A.L, Stevens J.B., Nathan,C.P. ,Seto E., Cafazzo A.J and Stintson N.J. 2014, A Smartphone-Based Pain Management App for Adolescents with Cancer: Establishing System requirements and a Pain care Algorithm based on Literature review, Interviews and Consensus, JMIR Res Protoc 19;3(1):e15. doi: 10.2196/resprot.3041.

[24] Galligioni, E., Piras, E.M., Galvagni, M., Eccher, C., Caramatti, S., Zanolli, D and Forti, S. 2015, Integrating mHealth in Oncology: Experience in the Province of Trento, JMIR Res Protoc 17(5):e114, doi: 10.2196/jmir.3743.

[25] Cappuro, D., Ganzinger, M., Perez-Lu, J. and Knaup, P. 2014. Effectiveness of eHealth interventions and information needs in palliative care; A systematic literature review, JMIR Res Protoc, 16,(3). doi: 10.2196/jmir.2812.

[26]Haque, Md.M, Mobile Based Symptom Management for Palliative Care. 2012. http://epublications.marquette.edu/dissertations mu/268/. Accesed $10^{\text {th }}$ May 2015

[27] Baum, F., MacDougall, C. and Smith, D. 2006. Participatory action research. Journal of Epidemiology and Community Health, 60(10), 854-857. doi:10.1136/jech.2004.028662

[28] Bilandzic, M. and Venable, J. 2011. Towards participatory action design research: adapting action research and design science research methods for urban informatics. Journal of Community Informatics http://ci-journal.net/index.php/ciej/article/view/786/804,7(3). Acessed on 10th November 2015.

[29] Teddlie, C. and Yu, F. 2007. Mixed Methods Sampling A Typology With Examples, Journal of Mixed Methods Research. 1(1);77-100, doi: 10.1177/2345678906292430

[30] Kallen, M. A., Yang, D. and Haas, N. 2012.A technical solution to improving palliative and hospice care. Support Care Cancer, 20(1), 167-174.

[31] Mirkovic,J., Kaufman, D.R. and Ruland, C.M. 2014. Supporting cancer patients in illness management: usability evaluation of a mobile app. JMIR Mhealth Uhealth.13;2(3):e33. doi: 10.2196/mhealth.3359.

[32] Enguidanos, S., Portanova, J. and Stone,S. 2014. Using a Mobile Phone to Assess and Monitor Pain for Diverse Seriously Ill Older Adults: A Feasibility Study, J Pain Symptom Manage,47( 2 ), 476. doi:10.1016/j.jpainsymman.2013.12.137.

[33] Daveson BA, Simon ST, Benalia H, Downing J, Higginson IJ, Harding R, Bausewein C. Are we heading in the same direction? European and African doctors' and nurses' views and experiences regarding outcome measurement in palliative care, Palliative Medicine, 2011 26(3), 242-249.

[34] Harding,R.,Selman,L.,Agupio,G.,Dinat,N.,Downing,J.,Gwyther,L.and Higginson,I.J. 2010. Validation of a core outcome measure for palliative care in Africa: the APCA African Palliative Outcome Scale, Health and Quality of Life Outcomes, 8(10), doi: 10.1186/1477-7525-8-10.

[35] GSMA Intelligence. The Mobile Economy Africa 2016. Website.

https://www.gsmaintelligence.com/research/?file=3bc21 ea879a5b217b64d62fa24c55bdf\&download Accessed on $28 / 02 / 2017$

[36] The Communications Authority of Kenya. First Quarter Sector Statistics Report for the Financial Year 2016/2017 (July-September-2016). Website

http://www.ca.go.ke/images/downloads/STATISTICS/Sector\%20Statistics\%20Report\%20Q1\%2020162017.pdf Accessed on $28^{\text {th }} 022017$

[37] The National Communications Authority, Telecom Voice Subscription. website http://www.nca.org.gh/industry-data-2/market-share-statistics-2/voice-2/ Accessed on 28/02/2017

[38]World Health Organization. Cancer Fact sheet. website

http://www.who.int/nmh/publications/ncd report chapter1.pdf Accessed on $28^{\text {th }} 022017$. 
[39] Dix O. Impact of the APCA African Palliative Outcome Scale (POS) on care and practice Website http://pos-pal.org/doca/Impact_of_APCA_POS.pdf Accessed on 12/02/ 2017 